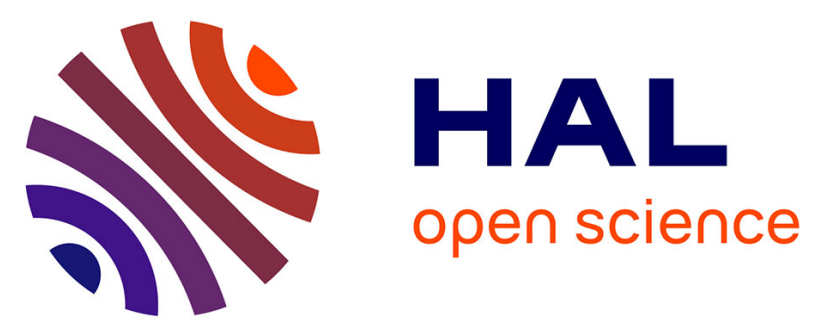

\title{
Feasibility, Safety and Efficacy of Transcatheter Aortic Valve Replacement Without Balloon Pre-Dilation: A Systematic Review and Meta-Analysis
}

Vincent Auffret, Ander Regueiro, Francisco Campelo-Parada, Maria del Trigo, Olivier Chiche, Chekrallah Chamandi, Rishi Puri, Josep Rodes-Cabau

\section{To cite this version:}

Vincent Auffret, Ander Regueiro, Francisco Campelo-Parada, Maria del Trigo, Olivier Chiche, et al.. Feasibility, Safety and Efficacy of Transcatheter Aortic Valve Replacement Without Balloon PreDilation: A Systematic Review and Meta-Analysis. Catheterization and Cardiovascular Interventions, 2017, 90 (5), pp.839-850. 10.1002/ccd.27040 . hal-01636358

\section{HAL Id: hal-01636358}

\section{https://hal-univ-rennes1.archives-ouvertes.fr/hal-01636358}

Submitted on 16 Nov 2017

HAL is a multi-disciplinary open access archive for the deposit and dissemination of scientific research documents, whether they are published or not. The documents may come from teaching and research institutions in France or abroad, or from public or private research centers.
L'archive ouverte pluridisciplinaire HAL, est destinée au dépôt et à la diffusion de documents scientifiques de niveau recherche, publiés ou non, émanant des établissements d'enseignement et de recherche français ou étrangers, des laboratoires publics ou privés. 


\title{
Feasibility, Safety and Efficacy of Transcatheter Aortic Valve
}

\section{Replacement Without Balloon Pre-Dilation:}

\section{A Systematic Review and Meta-Analysis}

\author{
Vincent Auffret ${ }^{1,2}, \mathrm{MD}, \mathrm{MSc}$, Ander Regueiro ${ }^{1}, \mathrm{MD}$, Francisco Campelo-Parada ${ }^{1}, \mathrm{MD}$, María \\ del Trigo ${ }^{1}, \mathrm{MD}$, Olivier Chiche ${ }^{1}$, MD, Chekrallah Chamandi, MD ${ }^{1}$, Rishi Puri ${ }^{1}$, MBBS, PhD, \\ Josep Rodés-Cabau ${ }^{1}$, MD.
}

\begin{abstract}
${ }^{1}$ Quebec Heart \& Lung Institute, Laval University, Quebec City, Quebec, Canada
${ }^{2}$ Rennes 1 University, Signal and Image Processing Laboratory, Rennes, France
\end{abstract}

Short title: Feasibility, safety and efficacy of direct TAVR.

Conflict of interest statement: Dr. Josep Rodés-Cabau has received research grants from Edwards Lifesciences, Medtronic and St Jude Medical. Dr Vincent Auffret received fellowship support from the Fédération Française de Cardiologie and research grants from Abbott, Edwards Lifescience, Medtronic, Biosensors, Terumo and Boston Scientific. The other authors do not report any potential conflict of interest.

\section{Address for correspondence:}

Josep Rodés-Cabau, MD.

Quebec Heart \& Lung Institute,

Laval University,

2725 Chemin Ste-Foy, G1V 4GS

Quebec City, Quebec, Canada

Phone: 418-6568711; FAX: 418-6564544

E-mail: josep.rodes@criucpq.ulaval.ca

\section{Word count: 5036.}




\section{ABSTRACT}

Objectives: To evaluate the feasibility, safety and efficacy of direct transcatheter aortic valve replacement (TAVR), i.e. TAVR without balloon pre-dilation (BPD), by performing a systematic review and meta-analysis of available evidence.

Background: Avoiding BPD during TAVR was shown to be feasible in previous studies but the risks and benefits of this technique are unknown owing to the limited number of patients included in these studies.

Methods: We performed a systematic search for studies comparing direct TAVR vs. TAVR performed with BPD. Crude risk ratios (RRs) or mean differences and 95\% confidence intervals $(\mathrm{CI})$ for each endpoint were calculated using random effects models.

Results: Twenty studies including 3586 patients (1606 undergoing direct TAVR) were selected for the analysis. Mean device success with direct TAVR was $88 \%$ with $<5 \%$ of bailout techniques. There were no differences between direct and BPD-TAVR in short-term (inhospital or 30-day) mortality (RR:1.06; 95\% CI:0.78-1.43) or cerebrovascular events (RR:0.92; 95\% CI:0.58-1.46). Direct TAVR associated with reduced moderate or severe paravalvular leak post-TAVR (RR:0.59; 95\% CI:0.36-0.98) but not with a reduced risk of permanent pacemaker implantation (RR:0.85, 95\% CI:0.71-1.02). A slight increase in postdilation was observed in direct transfemoral-TAVR recipients (RR:1.2; 95\%CI:1.00-1.44).

Conclusion: Direct TAVR is feasible and safe. However, given the unadjusted nature of our results, uncertainties remain regarding the independent effect of direct TAVR on outcomes post-TAVR. Randomized studies are warranted to determine the potential benefits of direct TAVR.

Keywords: Aortic Stenosis; Transcatheter Aortic Valve Implantation; Balloon Valvuloplasty. 


\section{INTRODUCTION}

Avoidance of balloon pre-dilation (BPD) during transcatheter aortic valve replacement (TAVR), a strategy known as direct TAVR, has recently emerged as part of a general shift towards simplified and more straightforward procedures ${ }^{1}$. Although BPD was deemed mandatory as a preparatory step in the early days of TAVR, some small feasibility studies showed high procedural success rates when omitting $\mathrm{BPD}^{1,2}$. As shown in recent series ${ }^{3}$, balloon aortic valvuloplasty per se carries risks of permanent pacemaker implantation (PPI), severe aortic regurgitation, and stroke ranging from 0.5 to $2 \%$, that represent the rationale supporting direct TAVR. An aggressive pre-dilation of the aortic valve and the adjacent left ventricular outflow tract may indeed increase the rate of $\mathrm{PPI}^{4}$ and significant paravalvular leaks (PVL) post-TAVR especially with self-expanding valves $(\mathrm{SEV})^{5,}{ }^{6}$. Similarly, beyond a seemingly obvious time saving, it has been hypothesized that by reducing manipulation of the aortic arch and degenerated valve and avoiding rapid pacing runs, direct TAVR might lead to a reduction of acute cerebrovascular events (CVE) related to debris embolization or sustained impaired hemodynamic states. However, currently, data supporting direct TAVR are mainly limited to small single-center studies. Moreover, it has recently been demonstrated in a study using diffusion-weighted magnetic resonance imaging post-TAVR that direct TAVR might actually result in a higher volume of cerebral ischemic lesions ${ }^{7}$.

Given the current lack of consensus, we assessed the feasibility, safety and efficacy of direct TAVR by performing a systematic review and meta-analysis of available evidence. 


\section{METHODS}

\section{Search strategy}

A systematic review of published literature on direct TAVR was conducted in accordance with the guidance and reporting items specified in the Preferred Reported Items for Systematic Reviews and Meta-Analysis (PRISMA) statement ${ }^{8}$. A computerized search was performed to identify all relevant studies from PudMed and EMBASE databases. The following keywords or terms were used: transcatheter aortic valve, TAVI, TAVR, transcutaneous aortic valve, percutaneous aortic valve, direct, predilation, predilatation, dilation, dilatation, balloon, and valvuloplasty. The MeSH terms: Transcatheter Aortic Valve Replacement and Balloon Valvuloplasty were also used. The search strategy is outlined in the supplemental appendix. Databases were last accessed on July $11^{\text {th }} 2016$. In addition to the computerized search, we manually reviewed the bibliography of all included articles (V.A) to ensure complete inclusion of all possible studies.

\section{Eligibility criteria and study selection}

We deemed eligible any study of original design that compared results of direct TAVR with those of TAVR performed with BPD. We included studies in which quantitative raw data that enabled the calculation of crude risk ratios (RR) for dichotomous endpoints and mean difference (MD) for continuous endpoints were available. When potential overlapping study populations were detected (based on participating institutions and inclusion periods), the most recent publication or the publication with the most information of interest was included in the analysis. Case reports or studies published in a non-English language were excluded.

Two investigators (V.A. and A.R.) independently conducted the literature searches, study eligibility assessment and data extraction in duplicate. Any discrepancies were resolved by consensus by a third investigator (J.R.C.)

\section{Data extraction}


We extracted data of the patients and studies using a standardized data abstraction sheet. The following study-, patient- and procedure-related data were extracted from the main paper and accompanying supplemental appendix: study design; number of participating centers, region and period of enrolment, number of patients, exclusion criteria, periprocedural events definition, age, sex, baseline procedural risk assessment (by logistic European System for Cardiac Operative Risk Evaluation (EuroSCORE) or Society of Thoracic Surgeons Predicted Risk of Mortality score), number of patients with prior stroke, coronary artery disease and atrial fibrillation at baseline, access site, BEV and SEV rates, rates of patients requiring bail-out manoeuvres to cross the aortic valve or acute valve-in-valve.

\section{Endpoints}

Primary outcomes of the meta-analysis included short-term, either at discharge or at 30 days of follow-up as reported by the authors, all-cause mortality and CVE (stroke or transient ischemic attack). Secondary endpoints were rates of device success as defined by the Valve Academic Research Consortium ${ }^{9}$, need for balloon post-dilation, PPI, acute kidney injury (AKI) stage 2 or 3, moderate or severe PVL at discharge, and fluoroscopy time, total procedure time, total contrast used, and mean transvalvular gradient at discharge.

\section{Statistical analysis}

Crude RR and mean differences were the principal summary measures. Means and standard deviations of continuous endpoints were extracted from studies and used for the analysis. RRs were retrieved or calculated with the corresponding $95 \%$ confidence interval for each endpoint and entered in the primary analysis. Data across studies were combined using DerSimonian and Laird random effects models ${ }^{10}$. Consistency across studies was assessed with the Q-statistic and $\mathrm{I}^{2}$ index which takes values between $0 \%$ and $100 \%$, with values of

$25 \%$ typically suggesting low, 50\% moderate, and $75 \%$ large heterogeneity ${ }^{11}$. Significant heterogeneity was considered present for p-values $<0.10$ or an $\mathrm{I}^{2}>50 \%$. Main results were 
confirmed using Mantel-Haenszel fixed effect models in case of low heterogeneity. To assess the potential effect of publication bias, we inspected funnel plots for asymmetry and used the Harbord test for dichotomous outcomes and the Egger test for continuous endpoints as formal statistical tests ${ }^{12}$. In case of significant publication bias, we intended to adjust the pooled effect estimate using the non-parametric "trim and fill" method which estimates the number and results of potential missing studies resulting from publication bias ${ }^{13}$. Stratified analyses were performed according to the type of implanted valve and to the timing of publication (i.e. before or after January $1^{\text {st }} 2015$ ) whereas sensitivity analysis was performed by including only studies that reported outcomes separately for transfemoral (TF) implantation or had $<10 \%$ cases with alternative access routes in order to account for the different risk profile of patients undergoing TAVR via an alternative approach. Descriptive characteristics are presented as mean \pm standard deviation for continuous variables and frequencies and percentages for categorical variables. All reported p values are 2 -sided and a value of $<0.05$ was considered significant. Statistical analyses were performed in STATA software (version 13.0, STATA Corp., College Station, Texas) and RevMan (Version 5.3.5, Copenhagen: The Nordic Cochrane Centre, The Cochrane Collaboration).

\section{RESULTS}

\section{Selection of studies and population}

Figure 1 shows the PRISMA flow diagram. Following removal of duplicates, 2259 records were screened at the title and abstract level. Of these, 26 studies were retrieved in full text and examined for eligibility. In addition, 29 published abstracts were also retrieved through EMBASE database and evaluated. Finally, 17 published studies ${ }^{2,}$ 5-7, 14-26 and 3 abstracts ${ }^{27-29}$ fulfilled the inclusion criteria and were deemed eligible for the analysis (Table 1). Sixteen studies were observational, 4 used propensity-score matching to adjust for 
imbalance in baseline characteristics between groups and 1 study was a case-control study. All but 3 studies were single-center works.

A total of 3586 patients were included in this analysis, with 1606 patients who underwent direct TAVR. Almost all studies reported the use of computed tomography during the pre-TAVR screening but only 10 studies specifically reported the imaging method used for valve sizing of which 8 used computed tomography. Balloon-expandable valves were implanted in 2274 patients without obvious differences between groups in devices iterations used in 10 out of 12 studies which reported it (supplementary table 1). A TF approach was used in $84.6 \%$ of cases (2959/3499 patients with known access site). The mean device success for direct TAVR was $88 \%$. Ten studies reported rates ranging from $0.0 \%$ to $3.8 \%$ of bail-out techniques in case of difficulty crossing the aortic valve namely rescue BPD, "buddy-balloon" technique $^{30}$, and partial inflation of the distal tip of the delivery balloon. Among these studies, the maximum rate of rescue BPD was $1.8 \%$. Clinical and procedural characteristics of patients from selected studies are depicted in Table 2.

\section{Impact of direct TAVR on mortality and stroke}

Based on data from 16 studies $(n=3260)$, direct TAVR was not associated with shortterm all-cause mortality post-TAVR (RR: 1.06; 95\% CI: 0.78-1.43, $\mathrm{p}=0.72, \mathrm{I}^{2}=0 \%$ ) (Figure 2,

supplementary figure 1). Similarly, no association was shown with CVE (RR: 0.92; 95\% CI: 0.58-1.46, $\mathrm{p}=0.72,14$ studies, $\mathrm{n}=3143$ ) with low statistical heterogeneity across studies $\left(\mathrm{I}^{2}=4 \%\right)$. These results were confirmed with the use of fixed-effect models. There was no evidence of significant publication bias in the pooled estimates of primary outcomes either by funnel plot inspection or with the use of the Harbord test.

In stratified analyses by type of implanted valve, direct TAVR was associated with a significant reduction in short-term CVE in BEV recipients (RR: 0.51; 95\%CI: 0.26-0.99, $\mathrm{p}=0.05,9$ studies, $\mathrm{n}=1334$ ) but not in SEV recipients in limited data (2 studies, $\mathrm{n}=282$ ) 
(Figures 3 and 4,). Restricting the analysis to TF TAVR recipients or by timing of publication yielded results consistent with the main analysis (Figure 5, supplementary figure 2).

\section{Procedural outcomes}

Fluoroscopy time was not significantly different between groups (MD: -1.91 min; 95\% CI: $-4.25,0.43 ; \mathrm{p}=0.11,6$ studies, $\mathrm{n}=1289$ ), but procedural time was shorter (MD: -19.75 min; 95\% CI: $-36.87,-2.63 ; \mathrm{p}=0.02,5$ studies, $\mathrm{n}=508)$ and total contrast used lower (MD: 20.77 ml; 95\% CI:-28.95, -12.58; $\mathrm{p}=<0.001,8$ studies, $\mathrm{n}=1594)$ in direct TAVR recipients. Moderate to high statistical heterogeneity was demonstrated for these endpoints. Publication biases were also shown either by funnel plot inspection or by the Egger test for all endpoints. When applying the "trim and fill" method to adjust pooled estimates, results remained unchanged for total contrast used, were consistent with the main analysis for procedure time $(\mathrm{MD}=-29.39 \mathrm{~min} ; 95 \% \mathrm{CI}:-46.90,-11.88 ; \mathrm{p}=0.001)$ and suggested a reduced fluoroscopy time with direct TAVR (MD: -4.29 min; 95\% CI: -6.96, -3.16; p=0.002). No data were available from SEV recipients for stratified analysis and overall data were limited in the other stratified or sensitivity analyses (Table 3). Amongst direct TAVR patients, reduction of volume of contrast was consistent in all analyses; fluoroscopy time was significantly reduced in BEV recipients whereas procedure time was only reduced in TF TAVR recipients and in studies published since 2015 .

There was a significant association between direct TAVR and an increased rate of device success in the main analysis (RR: 1.03; 95\% CI: 1.00-1.05, p=0.02, 13 studies, $\mathrm{n}=2524)$ without evidence of statistical heterogeneity $\left(\mathrm{I}^{2}=5 \%\right)$ (Figure 2). Conversely, there was strong evidence of publication bias ( $\mathrm{p}$ for Harbord test=0.007). When adjusting the pooled estimates using the "trim and fill" method, direct TAVR remained associated with a trend towards increased device success (RR: 1.03 , 95\% CI: 0.99-1.06, p=0.06) which was 
consistent with the aggregate RR derived from a fixed effect model (RR: 1.03 95\% CI: 1.00$1.06, \mathrm{p}=0.07, \mathrm{I}^{2}=5 \%$ ). Stratified and sensitivity analyses demonstrated that this relationship was mainly driven by BEV recipients and studies published since 2015 (Figures 3 and 4, supplementary figure 2).

Direct TAVR was not associated with the need for balloon post-dilation in all analyses performed at the exception of a slight but significant increase in TF-TAVR recipients (Figures 2, 3 and 4, supplementary figures 1 and 2). There was no significant statistical heterogeneity across studies or evidence of publication bias for this endpoint.

\section{Post-procedural outcomes}

The risk of AKI was not significantly different between groups in all analyses performed (Figures 2, 3, and 4, supplementary figures 1 and 2) with a pooled estimate in the main analysis of 1.05 (95\% CI: $0.55-2.03, \mathrm{p}=0.88, \mathrm{I}^{2}=28 \%, 7$ studies, $\left.\mathrm{n}=1713\right)$. The Harbord test suggested publication bias $(\mathrm{p}=0.015)$. However results of the "trim and fill" method were consistent with the main analysis $(\mathrm{RR}=0.75$; $95 \% \mathrm{CI}: 0.38-1.48, \mathrm{p}=0.411)$.

Based on data from 15 studies $(\mathrm{n}=2853)$, there was a trend towards a lower risk of PPI with direct TAVR $(\mathrm{RR}=0.85,95 \% \mathrm{CI}: 0.71-1.02, \mathrm{p}=0.08)$ (Figure 2). Statistical heterogeneity was low $\left(\mathrm{I}^{2}=0 \%\right)$ and this result almost reached statistical significance when pooled estimate was derived from a fixed-effect model (RR: 0.84; 95\% CI: 0.70-1.00, $\mathrm{p}=0.05)$. No publication bias was demonstrated.

One study reported the rate of moderate or severe PVL but did not report the method used for its evaluation ${ }^{7}$. PVL was evaluated angiographically in one study ${ }^{5}$ and by echocardiography in all other studies included in the analysis of this endpoint (supplementary Figure 1). Data synthesis of 16 studies $(n=3187)$ suggested a reduced risk of moderate or severe PVL with direct TAVR (RR: 0.59; 95\% CI: 0.36-0.98, p=0.04). Statistical heterogeneity across studies was moderate $\left(\mathrm{I}^{2}=53 \%\right)$ but significant $(\mathrm{p}=0.006)$ and no 
publication bias was demonstrated ( $\mathrm{p}=0.11$ for Harbord test). This reduction was consistent with both type of valve (Figure 3 and 4) and in studies published before 2015 but did not reach statistical significance in studies published since 2015 (supplementary Figure 2). The sensitivity analysis in TF TAVR recipients (8 studies, $\mathrm{n}=2096$ ) did not show any association between direct TAVR and the rate of moderate or severe PVL (Figure 5).

Direct TAVR associated with reduced mean transvalvular gradient at discharge in data synthesis of 11 studies (MD: $-0.54 \mathrm{mmHg}$; 95\% CI:-0.95, -0.13, p=0.23, n=2219) (Table 3). There was no heterogeneity across studies $\left(\mathrm{I}^{2}=1 \%\right)$ but publication bias was demonstrated ( $\mathrm{p}$ for Egger test $=0.047$ ). Nonetheless, the pooled estimate adjusted using the "trim and fill" method was consistent with the main analysis $(\mathrm{MD}=-0.767 ; 95 \% \mathrm{CI}:-1.295 ;-0.239$, $\mathrm{p}=0.004)$. No analysis suggested an increased post-procedural mean gradient in direct TAVR recipients. On the contrary, there was a trend towards a decreased gradient with direct TAVR in BEV recipients (Table 3).

\section{DISCUSSION}

The results of the present meta-analysis demonstrate that direct TAVR is feasible with a high rate of device success, an infrequent need for bail-out techniques, and associates with reduced procedural times and no deleterious impact on short-term mortality or stroke.

Potential risks and benefits of BPD during TAVR procedures are summarized in Table 4. One of the main concerns of direct TAVR is the possible difficulty in crossing the severely stenotic native aortic valve with the transcatheter valve system. The present study showed that this occurred in a very low number of patients, with $<2 \%$ of cases requiring rescue BPD. Future studies with a large numbers of patients will need to determine the factors associated with direct TAVR failure. Direct TAVR associated with reduced procedural times. This may be explained by the avoidance of one procedural step (BPD), but other factors such 
as facilitated valve positioning may also contribute to this reduced time. BPD is usually associated with larger aortic orificial areas in addition to increasing AR severity. This may result in more pronounced movements of the valve system during the cardiac cycle making the final positioning more challenging. However, avoiding BPD in case of important or bulky calcifications may also result in valve migration following deployment of the prosthesis. Therefore, patients' selection for direct TAVR may be of paramount importance regarding the results of this technique.

Direct TAVR associated with higher rates of device success, reflecting the lower rate of significant PVL observed with this technique in studies included in the present analysis. Whereas improved valve positioning may have played a role in such results, these associations need to be interpreted with caution due to the unadjusted nature of data analyzed in the present study. Although beneficial effects of direct TAVR per se cannot be ruled out, several confounders such as device improvements or growing operator experience may have influenced our results. Moreover, the non-randomized nature of included studies may have introduced bias as the selection of a direct TAVR strategy was left at the operators discretion based on pre-TAVR evaluation. As demonstrated by Abramowitz et al. ${ }^{14}$, it is therefore likely that patients with favorable anatomical characteristics of the aortic valve and arch coupled with a lower calcific burden more often underwent direct TAVR. This is of particular importance as a high correlation between the volume of calcification and the severity of PVL has been previously demonstrated ${ }^{31}$. Importantly, direct TAVR resulted in no deleterious effect on valve hemodynamic and no increase in the need for balloon post-dilation in the main analysis, further suggesting that current transcatheter valve systems are able to successfully open the calcified valve leaflets without the need for preparing the stenotic valve with BPD.

Transcatheter Doppler studies have shown that any mechanical interaction with a severely calcified and stenotic aortic valve, including BPD, is associated with an increase in 
cerebral emboli ${ }^{32}$. It was therefore hypothesized that direct TAVR might reduce CVE by avoiding risks of debris embolization inherent with $\mathrm{BPD}^{3}$. However, a recent study challenged this hypothesis showing a higher volume of cerebral ischemic lesion on diffusion-weighted magnetic resonance imaging in patients receiving direct $\mathrm{TAVR}^{7}$. In the present study direct TAVR associated with similar rates of CVE in the main analysis and with a reduction of CVE in BEV recipients. Whilst these clinical results are reassuring, it could also reflect that the potential benefits from avoiding BPD may be partially thwarted by a higher mechanical interaction and subsequent embolic burden at the time of crossing the native aortic valve. Further studies should focus on the potential effects of direct TAVR on neurological events especially according to the type of valve used.

PPI occurs in $10-17 \%$ of patients in recent series using both valve types ${ }^{33,34}$ and thus remains a concern given the current shift towards treating lower surgical-risk patients. Nonetheless, the valve implantation is directly responsible for less than half of new conduction disturbances during TAVR as most of them occur during BPD especially if the balloon is larger than the minor axis of the aortic annulus ${ }^{14,35}$. This has been described by Lange et al. ${ }^{4}$ as a two-hit model where the first hit is inflicted by a large valvuloplasty balloon to the conduction system promoting the persistence of high-degree atrioventricular block followed by a second hit by the valve frame. In their large series, Bernardi et al. ${ }^{29}$ demonstrated that BPD was associated with a 1.8-fold higher risk of new-onset persistent left bundle branch block compared with direct TAVR. These data, along with the trend towards a lower risk of PPI demonstrated in the present study, suggest that direct TAVR has the potential to reduce conduction disturbances and ultimately PPI in selected high-risk patients such as in case of pre-existent right bundle branch-block or in SEV recipients.

\section{Limitations}


Several limitations of the present analysis warrant consideration. First, as previously discussed, some limitations are inherent to the comparison of BPD with direct TAVR, a technique of more recent emergence which in a non-randomized setting is inevitably confounded by patient selection, device iterations and operator experience. Moreover, most of the included studies were small single-center ones without adjusted analyses regarding the outcomes of interest. We used crude RR/MD as our principal summary measures, thereby making it impossible to identify the independent influence of direct TAVR on our endpoints. Therefore, all associations identified in the present study should be regarded as hypothesisgenerating and do not allow any conclusion regarding causality. Moreover, benefits of BPD and impact of its avoidance may depend on the implanted valve type as suggested by the differing results of stratified analysis regarding CVE and PVL in the present study. These issues are currently evaluated in dedicated randomized trials (The preDIlatation in tRanscathEter aortiC Valve implanTation Trial [DIRECT], NCT02448927; TAVI Without Balloon Predilatation of the Aortic Valve SAPIEN 3 [DIRECTAVI], NCT02729519). Finally, very few data exist regarding moderate $\mathrm{BPD}^{4,14}$ which could represent a strategy harboring the theoretical advantages of BPD whilst limiting its risks.

\section{CONCLUSION}

Direct TAVR is a feasible and safe technique that exhibits similar rates of short-term mortality and CVE compared with TAVR with prior BPD. Future works should identify the most suitable patients for this technique to further improve its results. However, owing to inherent limitations of studies included in this meta-analysis, the independent effect of direct TAVR remains uncertain and a randomized evaluation comparing this technique to conventional BPD-TAVR is warranted.

\section{REFERENCES}


1. Grube E, Naber C, Abizaid A, Sousa E, Mendiz O, Lemos P, Kalil Filho R, Mangione J, Buellesfeld L. Feasibility of transcatheter aortic valve implantation without balloon predilation: A pilot study. JACC Cardiovasc Interv 2011;4:751-757

2. Mollmann H, Kim WK, Kempfert J, Blumenstein J, Liebetrau C, Nef H, Van Linden A, Walther T, Hamm C. Transfemoral aortic valve implantation of edwards sapien xt without predilatation is feasible. Clin Cardiol 2014;37:667-671

3. Eltchaninoff H, Durand E, Borz B, Furuta A, Bejar K, Canville A, Farhat A, Fraccaro C, Godin M, Tron C, Sakhuja R, Cribier A. Balloon aortic valvuloplasty in the era of transcatheter aortic valve replacement: Acute and long-term outcomes. Am Heart J 2014;167:235-240

4. Lange P, Greif M, Vogel A, Thaumann A, Helbig S, Schwarz F, Schmitz C, Becker C, D'Anastasi M, Boekstegers P, Pohl T, Laubender RP, Steinbeck G, Kupatt C. Reduction of pacemaker implantation rates after corevalve( $\mathrm{r}$ ) implantation by moderate predilatation. EuroIntervention 2014;9:1151-1157

5. Fiorina C, Maffeo D, Curello S, Lipartiti F, Chizzola G, D'Aloia A, Adamo M, Mastropierro R, Gavazzi E, Ciccarese C, Chiari E, Ettori F. Direct transcatheter aortic valve implantation with self-expandable bioprosthesis: Feasibility and safety. Cardiovasc Revasc Med $2014 ; 15: 200-203$

6. Toutouzas K, Latsios G, Stathogiannis K, Drakopoulou M, Synetos A, Sanidas E, Mastrokostopoulos A, Trantalis G, Kaitozis O, Lazaros G, Yuecel S, Gerckens U, Grube E, Tousoulis D. One-year outcomes after direct transcatheter aortic valve implantation with a self-expanding bioprosthesis. A two-center international experience. Int $J$ Cardiol 2016;202:631-635

7. Bijuklic K, Haselbach T, Witt J, Krause K, Hansen L, Gehrckens R, Rieß FC, Schofer J. Increased risk of cerebral embolization after implantation of a balloon-expandable aortic valve without prior balloon valvuloplasty. JACC Cardiovasc Interv 2015;8:1608-1613

8. Moher D, Liberati A, Tetzlaff J, Altman DG. Preferred reporting items for systematic reviews and meta-analyses: The prisma statement. Open Med 2009;3:e123-130 
9. Kappetein AP, Head SJ, Généreux P, Piazza N, Van Mieghem NM, Blackstone EH, Brott TG, Cohen DJ, Cutlip DE, Van Es GA, Hahn RT, Kirtane AJ, Krucoff MW, Kodali S, Mac KMJ, Mehran R, Rodés-Cabau J, Vranckx P, Webb JG, Windecker S, Serruys PW, Leon MB. Updated standardized endpoint definitions for transcatheter aortic valve implantation: The valve academic research consortium-2 consensus document. Eur Heart J 2012;33:2403-2418b

10. DerSimonian R, Laird N. Meta-analysis in clinical trials. Control Clin Trials. 1986;7:177-188

11. Higgins JP, Thompson SG. Quantifying heterogeneity in a meta-analysis. Stat Med 2002;21:1539-1558

12. Harbord RM, Egger M, Sterne JA. A modified test for small-study effects in meta-analyses of controlled trials with binary endpoints. Stat Med 2006;25:3443-3457

13. Duval S, Tweedie R. Trim and fill: A simple funnel-plot-based method of testing and adjusting for publication bias in meta-analysis. Biometrics. 2000;56:455-463

14. Abramowitz Y, Jilaihawi H, Chakravarty T, Kashif M, Matar G, Hariri B, Patel J, Sharma RP, Cheng W, Makkar RR. Feasibility and safety of balloon-expandable transcatheter aortic valve implantation with moderate or without predilatation. EuroIntervention 2016;11:1132-1139

15. Conradi L, Schaefer A, Seiffert M, Schirmer J, Schaefer U, Schon G, Blankenberg S, Reichenspurner H, Treede H, Diemert P. Transfemoral tavi without pre-dilatation using balloon-expandable devices: A case-matched analysis. Clin Res Cardiol 2015;104:735-42.

16. Conradi L, Seiffert M, Schirmer J, Koschyk D, Blankenberg S, Reichenspurner H, Diemert P, Treede H. Transapical transcatheter aortic valve implantation without prior balloon aortic valvuloplasty: Feasible and safe. Eur J Cardiothorac Surg 2014;46:61-66

17. Islas F, Almeria C, Garcia-Fernandez E, Jimenez P, Nombela-Franco L, Olmos C, MarcosAlberca P, Cuadrado A, Fernandez-Ortiz A, Macaya C, Perez de Isla L. Usefulness of echocardiographic criteria for transcatheter aortic valve implantation without balloon predilation: A single-center experience. J Am Soc Echocardiogr 2015;28:423-429

18. Kempfert J, Meyer A, Kim WK, van Linden A, Arsalan M, Blumenstein J, Mollmann H, Walther T. First experience without pre-ballooning in transapical aortic valve implantation: A propensity score-matched analysis. Eur J Cardiothorac Surg 2015;47:31-38 
19. Kim WK, Praz F, Blumenstein J, Liebetrau C, Gaede L, Van Linden A, Hamm C, Walther T, Windecker S, Mollmann H. Transfemoral aortic valve implantation of edwards sapien 3 without predilatation. Catheter Cardiovasc Interv 2016 doi: 10.1002/ccd.26464.

20. Kochman J, Kołtowski Ł, Huczek Z, Scisło P, Bakoń L, Wilimski R, Rymuza B, Opolski G. Direct transcatheter aortic valve implantation - one-year outcome of a case control study. Postepy Kardiol Interwencyjnej 2014;10:250-257

21. Wong SC, Pawar S, Minutello RM, Horn EM, Skubas NJ, Devereux RB, Salemi A. Device success and 30-day clinical outcome in patients undergoing preimplant valvuloplasty in transfemoral versus omitting valvuloplasty in transapical transcatheter aortic valve replacement. J Thorac Cardiovasc Surg 2015;150:1111-1117

22. Van Linden A, Kim WK, Liebetrau C, Doss M, Hecker F, Arsalan M, Blumenstein J, Möllmann H, Walther T. Simplified transapical aortic valve implantation using the sapien 3 valve without preballooning. Innovations (Phila) 2015;10:406-409

23. Wendler O, Dworakowski R, Monaghan M, MacCarthy PA. Direct transapical aortic valve implantation: A modified transcatheter approach avoiding balloon predilatation. Eur $J$ Cardiothorac Surg 2012;42:734-736

24. Aggarwal SK, Delahunty N, Wong B, Tamimi AN, Reinthaler M, Cheang MH, Roberts N, Yap J, Ozkor M, Mullen MJ. Balloon-expandable transcatheter aortic valves can be successfully and safely implanted transfemorally without balloon valvuloplasty. J Interv Cardiol 2016;29:319-324

25. Bandali A, Parry-Williams G, Kassam A, Palmer S, Williams PD, de Belder MA, Owens A, Goodwin A, Muir DF. Direct transfemoral transcatheter aortic valve implantation without balloon pre-dilatation using the edwards sapien xt valve. Catheter Cardiovasc Interv 2016 doi: $10.1002 / \mathrm{ccd} .26564$

26. Pagnesi M, Jabbour RJ, Latib A, Kawamoto H, Tanaka A, Regazzoli D, Mangieri A, Montalto C, Ancona MB, Giannini F, Chieffo A, Montorfano M, Monaco F, Castiglioni A, Alfieri O, Colombo A. Usefulness of predilation before transcatheter aortic valve implantation. The Am J Cardiol 2016;118:107-112 
27. Lettieri C, Romano M, Baccaglioni N, Buffoli F, Rosiello R, Agostini F, Fiorani V, Pacchioni R, Rambaldini M, Zanini R. Transcatheter aortic valve implantation without balloon predilation: A non-randomized single centre experience. G Ital Cardiol 2014;15:e30

28. Nielsen NE, Ahn H, Baranowski J, Dahlin LG, Nylander E, Wallby L. Transcatheter aortic valve implantation without prior balloon dilatation-a non-randomized single centre experience. J Am Coll Cardiol 2013;62:B218

29. Bernardi FL, Ribeiro HB, Carvalho LA, Sarmento-Leite R, Mangione JA, Lemos PA, Abizaid A, Grube E, Rodes Cabau J, De Brito Jr FS. Direct transcatheter heart valve implantation versus implantation with balloon predilatation: Insights from the brazilian tavr registry. J Am Coll Cardiol 2016;67:415

30. Noble S, Roffi M. Retrograde aortic valve crossing of the corevalve prosthesis using the buddy balloon technique. Catheter Cardiovasc Interv 2014;84:897-899

31. Khalique OK, Hahn RT, Gada H, Nazif TM, Vahl TP, George I, Kalesan B, Forster M, Williams MB, Leon MB, Einstein AJ, Pulerwitz TC, Pearson GD, Kodali SK. Quantity and location of aortic valve complex calcification predicts severity and location of paravalvular regurgitation and frequency of post-dilation after balloon-expandable transcatheter aortic valve replacement. JACC Cardiovasc Interv 2014;7:885-894

32. Kahlert P, Al-Rashid F, Dottger P, Mori K, Plicht B, Wendt D, Bergmann L, Kottenberg E, Schlamann M, Mummel P, Holle D, Thielmann M, Jakob HG, Konorza T, Heusch G, Erbel R, Eggebrecht H. Cerebral embolization during transcatheter aortic valve implantation: A transcranial doppler study. Circulation 2012;126:1245-1255

33. Holmes DR, Jr., Nishimura RA, Grover FL, Brindis RG, Carroll JD, Edwards FH, Peterson ED, Rumsfeld JS, Shahian DM, Thourani VH, Tuzcu EM, Vemulapalli S, Hewitt K, Michaels J, Fitzgerald S, Mack MJ. Annual outcomes with transcatheter valve therapy: From the sts/acc tvt registry. J Am Coll Cardiol 2015;66:2813-2823

34. Walther T, Hamm CW, Schuler G, Berkowitsch A, Kotting J, Mangner N, Mudra H, Beckmann A, Cremer J, Welz A, Lange R, Kuck KH, Mohr FW, Mollmann H, board Ge. 
Peri-operative results and complications in 15,964 transcatheter aortic valve implantations from the german aortic valve registry (gary). J Am Coll Cardiol 2015;65:2173-80

35. Nuis RJ, Van Mieghem NM, Schultz CJ, Tzikas A, Van Der Boon RM, Maugenest AM, Cheng J, Piazza N, Van Domburg RT, Serruys PW, De Jaegere PP. Timing and potential mechanisms of new conduction abnormalities during the implantation of the medtronic corevalve system in patients with aortic stenosis. Eur Heart J 2011;32:2067-2074 


\section{FIGURES LEGENDS}

\section{Figure 1- Flow chart of selected studies}

Flow diagram -based on the PRISMA statement- of included studies.

Figure 2- Summary RRs of dichotomous endpoints (main analysis).

Forest plot of summary RRs for the comparison of direct TAVR versus TAVR performed with BPD. RRs lower than 1 favor direct TAVR except for device success for which a RR greater than 1 favor direct TAVR. AKI=Acute Kidney Injury; BPD=Balloon pre-dilation; $\mathrm{CVE}=$ Cerebrovascular events; PPI=Permanent pacemaker implantation; PVL=Paravalvular leak; TAVR=Transcatheter aortic valve replacement.

Figure 3- Summary RRs of dichotomous endpoints (stratified analysis-BEV recipients)

Forest plot of summary RRs for the comparison of direct TAVR versus TAVR performed with BPD in BEV recipients. Interpretation as in Figure 2. BEV=Balloon-expandable valve. Other abbreviations as in Figure 2.

Figure 4- Summary RRs of dichotomous endpoints (stratified analysis-SEV recipients)

Forest plot of summary RRs for the comparison of direct TAVR versus TAVR performed with BPD in SEV recipients. Interpretation as in Figure 2. SEV=Self-expandable valve. Other abbreviations as in Figure 2.

\section{Figure 5- Summary RRs of dichotomous endpoints (sensitivity analysis-TF TAVR)}

Forest plot of summary RRs for the comparison of direct TAVR versus TAVR performed with BPD in TF-TAVR recipients. Interpretation as in Figure 2. TF=Transfemoral. Other abbreviations

as

in

Figure

2. 

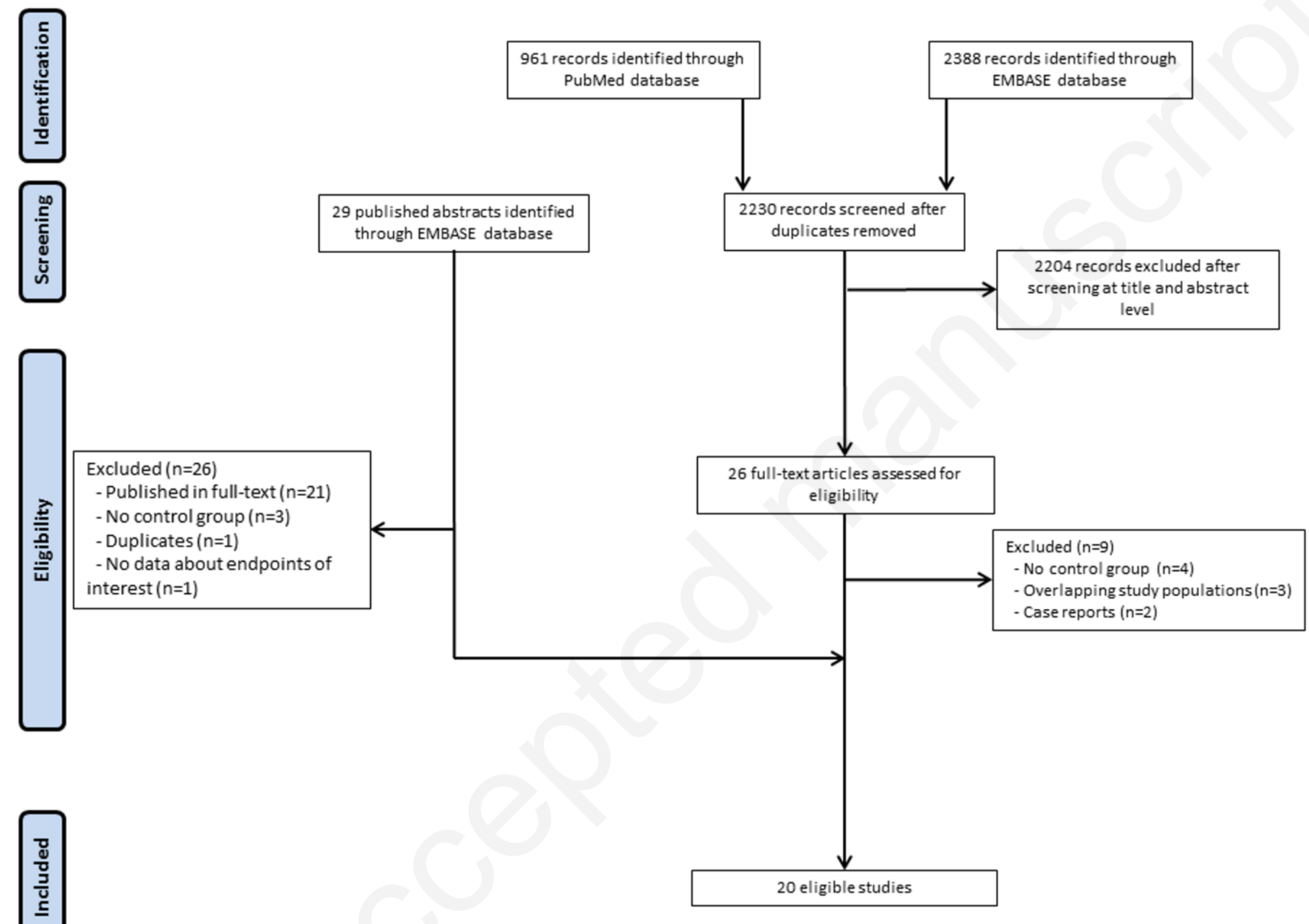


\begin{tabular}{|c|c|c|c|c|c|}
\hline Endpoint & $\begin{array}{l}\text { No. of } \\
\text { studies }\end{array}$ & $\begin{array}{l}\text { No. of } \\
\text { participants }\end{array}$ & $\mathrm{RR}(95 \% \mathrm{Cl})$ & $p$-value & I-squared \\
\hline Mortality & 16 & 3260 & $1.06(0.78-1.43)$ & 0.72 & $0 \%$ \\
\hline CVE & 14 & 3143 & $0.92(0.58-1.46)$ & 0.72 & $4 \%$ \\
\hline Device success & 13 & 2524 & $1.03(1.00-1.05)$ & 0.02 & $5 \%$ \\
\hline Post-dilation & 19 & 3566 & $1.08(0.92-1.27)$ & 0.35 & $11 \%$ \\
\hline PPI & 15 & 2853 & $0.85(0.71-1.02)$ & 0.08 & $0 \%$ \\
\hline AKI & 7 & 1713 & $1.05(0.55-2.03)$ & 0.88 & $28 \%$ \\
\hline$P V L \geq 2+$ & 16 & 3187 & $0.59(0.36-0.98)$ & 0.04 & $53 \%$ \\
\hline
\end{tabular}




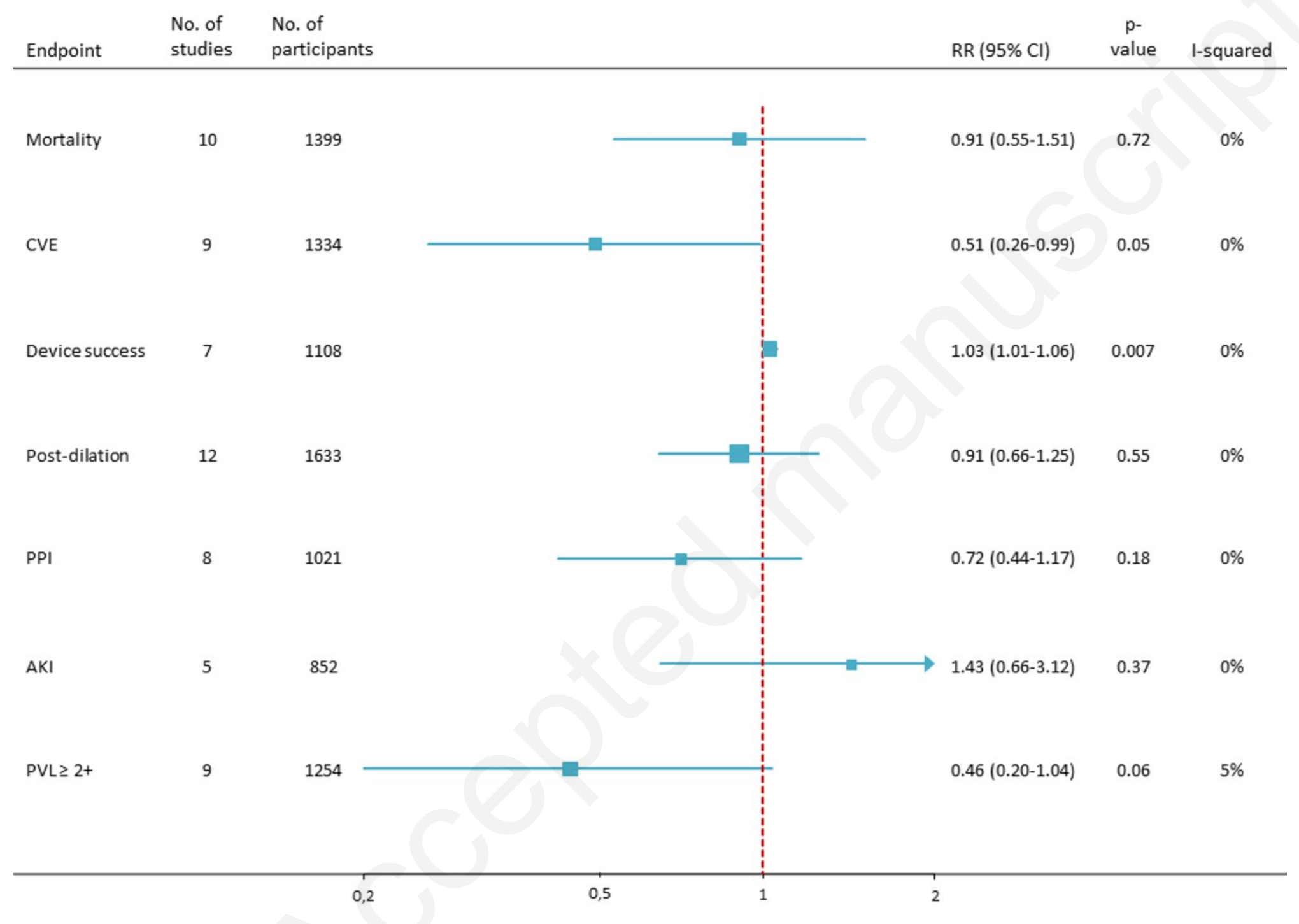




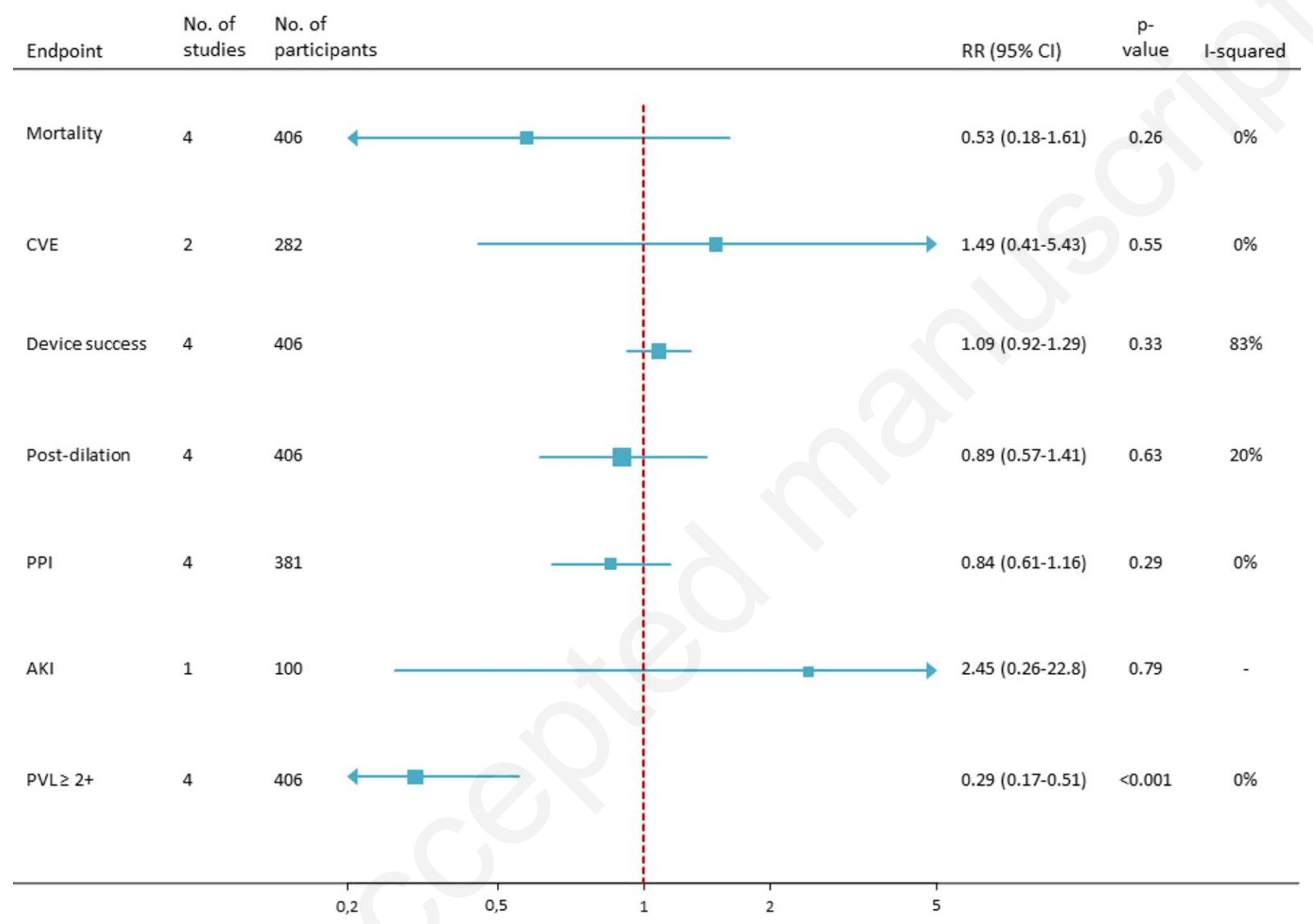




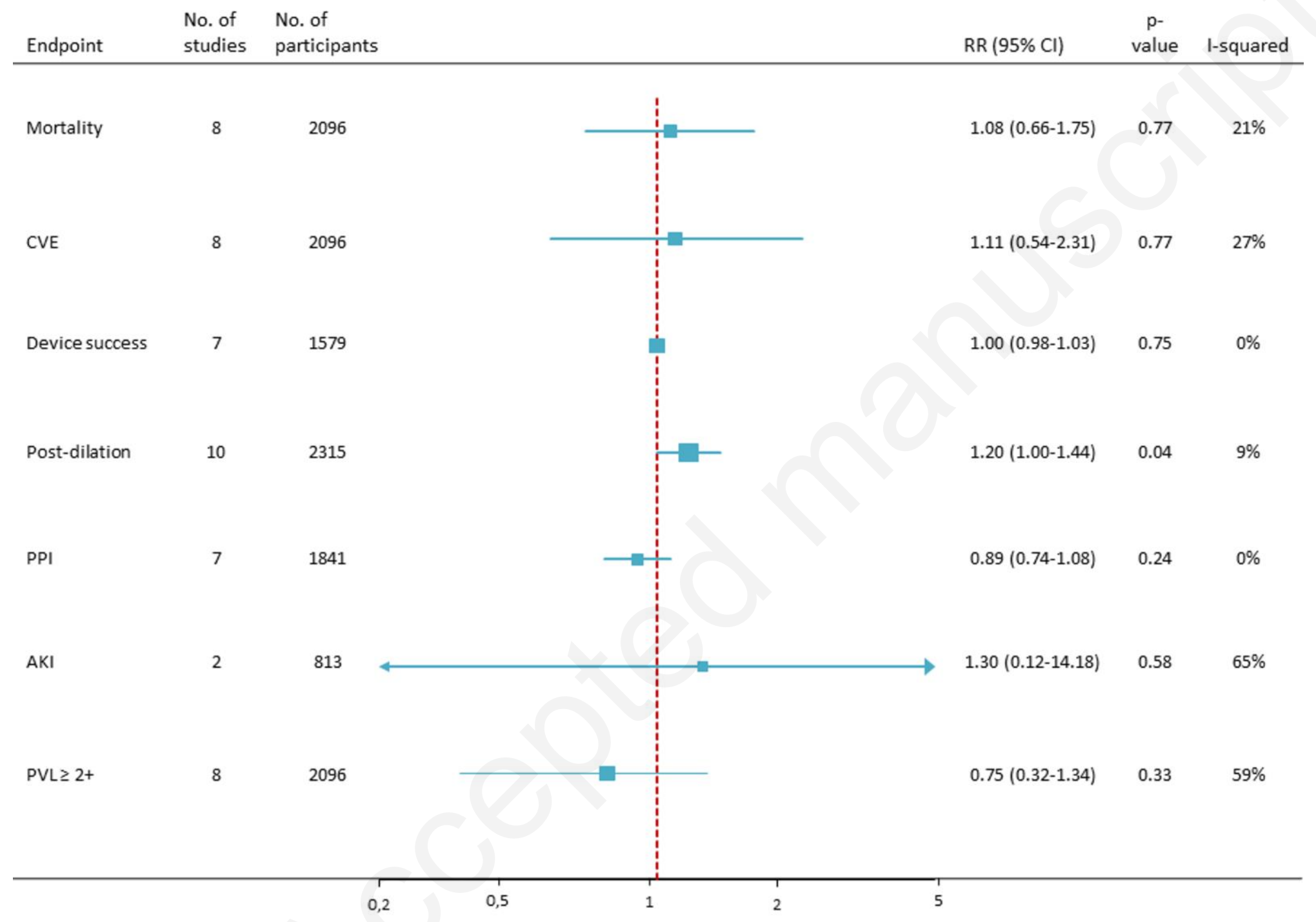


Table 1 - Characteristics of selected studies.

\begin{tabular}{|c|c|c|c|c|c|c|c|c|}
\hline Author Ref & Year & Region & $\begin{array}{c}\text { Centers } \\
(\text { n) }\end{array}$ & $\begin{array}{l}\text { Sample } \\
\text { size }(n)\end{array}$ & Design & Inclusion period & $\begin{array}{l}\text { Exclusion criteria / Direct TAVR } \\
\text { criteria }\end{array}$ & $\begin{array}{l}\text { Periprocedural } \\
\text { events criteria }\end{array}$ \\
\hline Abramowitz $^{15}$ & 2016 & USA & 1 & 513 & Observational & April 2012-December 2014 & $\begin{array}{l}\text { Valve-in-Valve, Prior BAV within } \\
\text { 30d, Regular BPD*. }\end{array}$ & VARC-2 \\
\hline Aggarwal $^{25}$ & 2016 & UK & 1 & 154 & Observational & March 2012-July 2014 & $\begin{array}{l}\text { Concomitant intervention, Valve-in- } \\
\text { Valve. }\end{array}$ & VARC-2 \\
\hline Bandali $^{26}$ & 2016 & UK & 1 & 81 & Observational & November 2010-March 2013 & $\begin{array}{l}\text { Valve-in-Valve. Excluded from direct } \\
\text { TAVR: BPD deemed necessary for } \\
\text { assessment of potential coronary } \\
\text { obstruction or valve sizing, extreme } \\
\text { calcification. }\end{array}$ & VARC \\
\hline Bernardi $^{30}$ & 2016 & Brazil & 22 & 761 & Observational & January 2008-January 2015 & $\begin{array}{l}\text { Valve-in-Valve, Use of Innovare } \\
\text { valve or ESV XT via TA approach. }\end{array}$ & VARC-2 \\
\hline Bijuklic $^{8}$ & 2015 & Germany & 1 & 87 & Observationnal & ND & $\begin{array}{l}\text { Refusal of or contra-indications to } \\
\text { DW-MRI, CVE within the prior } 6 \\
\text { months, renal failure, presentation } \\
\text { with cardiogenic shock or severe } \\
\text { hypotension, need for any other } \\
\text { cardiac surgical or interventional } \\
\text { procedure during or after } \\
\text { TAVR procedure before DW-MRI, } \\
\text { clinical apparent stroke within } 3 \text { days } \\
\text { post-TAVR. }\end{array}$ & VARC-2 \\
\hline
\end{tabular}




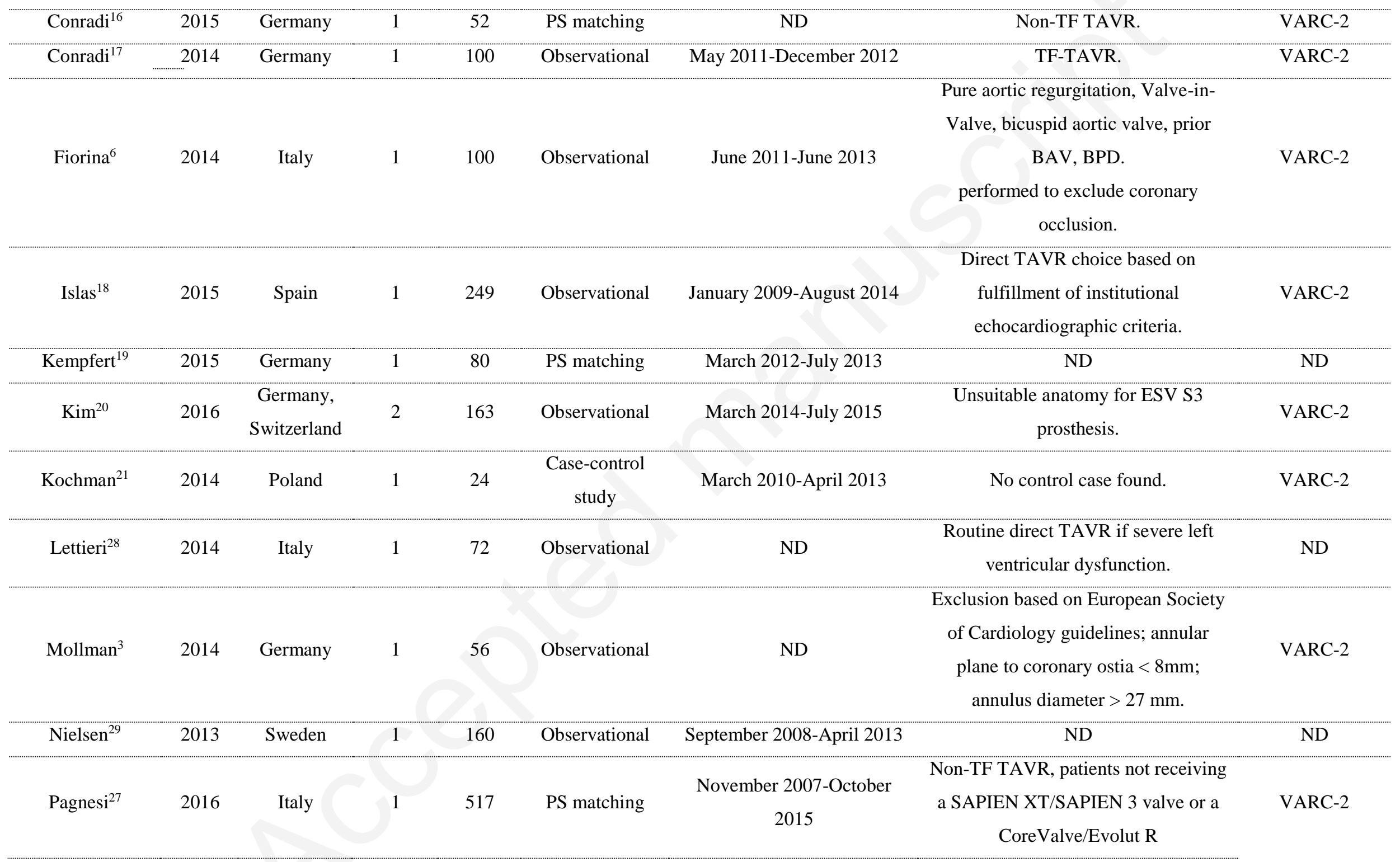




\begin{tabular}{|c|c|c|c|c|c|c|c|c|}
\hline Toutouzas 7 & 2016 & $\begin{array}{l}\text { Greece, } \\
\text { Germany }\end{array}$ & 2 & 210 & Observational & $\begin{array}{l}\text { January 2008-September } \\
2013\end{array}$ & ND & VARC-2 \\
\hline Van Linden ${ }^{23}$ & 2015 & Germany & 1 & 66 & Observational & 2013-2014 & ND & ND \\
\hline Wendler $^{24}$ & 2012 & UK & 1 & 20 & Observational & ND & ND & VARC \\
\hline Wong $^{22}$ & 2015 & USA & 1 & 121 & Observational & May 2012-December 2013 & $\begin{array}{l}\text { Valve-in-valve; patients included in a } \\
\text { protocol that mandated BPD. }\end{array}$ & VARC-2 \\
\hline
\end{tabular}

*BPD group consisted of "moderate" BPD with a mean pre-dilation balloon diameter/CT mean annulus diameter of 0.65/1.

$\mathrm{BAV}=$ Balloon aortic valvuloplasty; $\mathrm{BPD}=$ Balloon pre-dilation; $\mathrm{CVE}=$ Cerebrovascular events; DW-MRI= Diffusion-weighted magnetic resonance imaging; ESV S3= Edwards valve Sapien 3; ESV XT= Edwards valve Sapien XT; ND= No Data; PS=Propensity score; TA= Transapical; TAVR=Transcatheter aortic valve replacement; TF=Transfemoral; UK= United Kigndom; USA= United States of America; VARC= Valve Academic Research Consortium. 
Table 2- Clinical and procedural characteristics of patients from selected studies

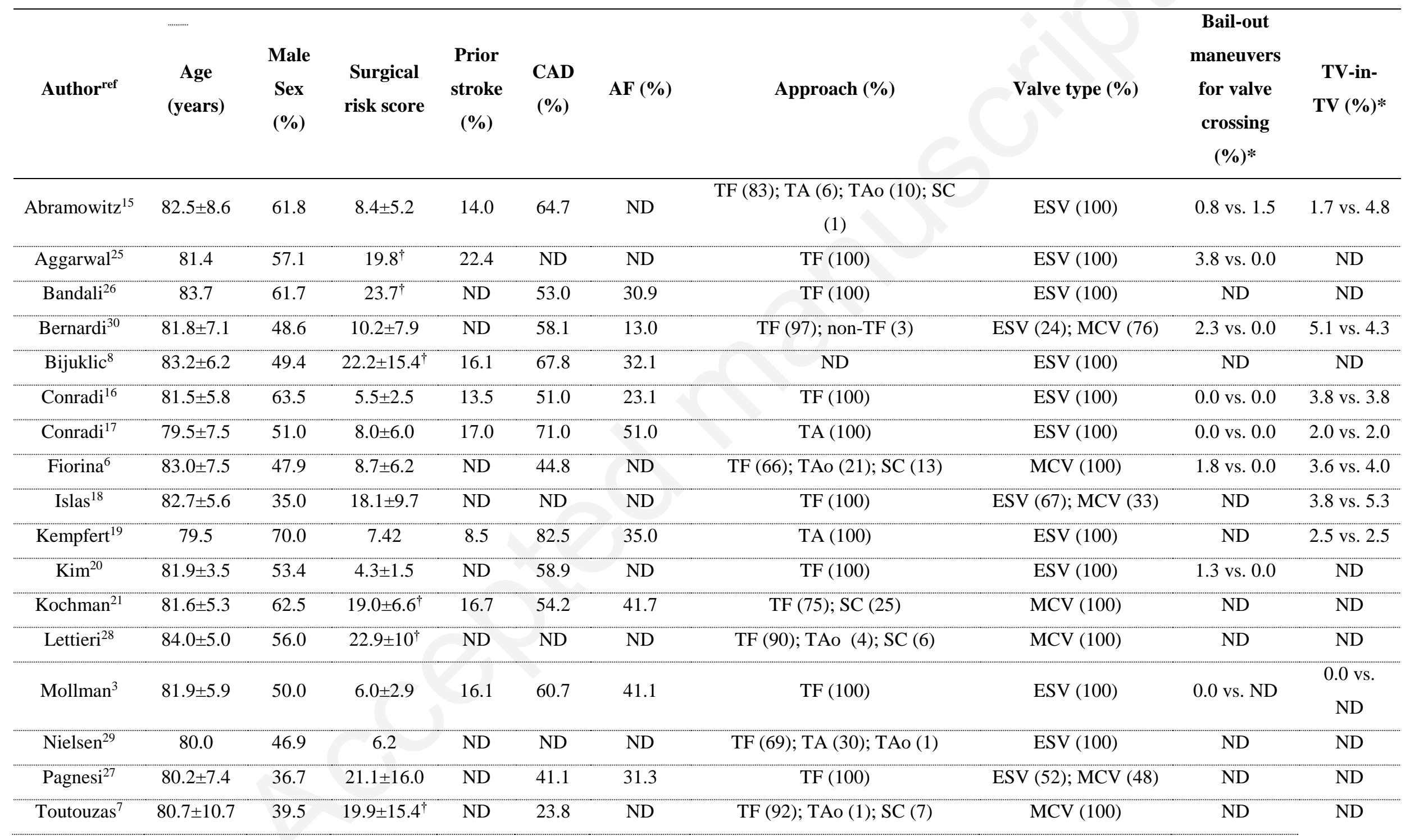




\begin{tabular}{|c|c|c|c|c|c|c|c|c|c|c|}
\hline Van Linden ${ }^{23}$ & $83.0 \pm 6.7$ & 61.7 & $7.5 \pm 5.2$ & 16.5 & 74.7 & 45.6 & TA (100) & ESV (100) & 0.0 vs. ND & 0.0 vs 0.0 \\
\hline Wendler ${ }^{24}$ & $82.0 \pm 3.0$ & 77.0 & $30.0 \pm 2.0^{\dagger}$ & 50.0 & ND & ND & TA (100) & ESV (100) & ND & ND \\
\hline Wong ${ }^{22}$ & $84.4 \pm 7.1$ & 49.0 & $8.9 \pm 4.9$ & 15.7 & ND & 39.7 & TF (59); TA (41) & ESV (100) & 0.0 vs. 0.0 & ND \\
\hline
\end{tabular}

* Direct TAVR group vs. BPD group

$\dagger$ Logistic EuroSCORE I if $\dagger$; Society of Thoracic Surgeon Predicted Risk of Mortality otherwise.

+ Baseline characteristics were unavailable for the matched cohorts and thus were retrieved from the entire cohort ( $\mathrm{n}=206)$.

$\mathrm{AF}=$ Atrial fibrillation; $\mathrm{BPD}=\mathrm{Balloon}$ pre-dilation; $\mathrm{CAD}=$ Coronary artery disease; $\mathrm{ESV}=$ Edwards Sapien Valves; $\mathrm{MCV}=\mathrm{Medtronic}$ Corevalve; $\mathrm{ND}=\mathrm{No}$

Data;TA=Transapical; TAo= Transaortic; $\mathrm{TF}=$ Transfemoral; TV-in-TV=Transcatheter valve within a transcatheter valve; $\mathrm{SC}=\mathrm{Sub}-\mathrm{clavian}$. 
Table 3-Results of analyses for continuous endpoints

\begin{tabular}{|c|c|c|c|c|c|}
\hline Endpoint & $\begin{array}{c}\text { Number of } \\
\text { studies } \\
\end{array}$ & $\begin{array}{c}\text { Number of } \\
\text { patients } \\
\end{array}$ & MD $(95 \%$ CI $)$ & p-value & I-squared \\
\hline \multicolumn{6}{|l|}{ Main analysis } \\
\hline Fluoroscopy time, min & 6 & 1289 & $-1.91(-4.25,0.43)$ & 0.11 & $84 \%$ \\
\hline Procedure time, $\min$ & 5 & 508 & $-19.75(-36.87,-2.63)$ & 0.02 & $88 \%$ \\
\hline Total contrast used, $\mathrm{ml}$ & 8 & 1594 & $-20.77(-28.95,-12.58)$ & $<0.001$ & $40 \%$ \\
\hline Post-procedural mean gradient, $\mathrm{mm} \mathrm{Hg}$ & 11 & 2219 & $-0.54(-0.95,-0.13)$ & 0.01 & $1 \%$ \\
\hline \multicolumn{6}{|l|}{ BEV patients } \\
\hline Fluoroscopy time, min & 5 & 772 & $-2.49(-4.96,-0.02)$ & 0.05 & $84 \%$ \\
\hline Procedure time, $\min$ & 4 & 259 & $-18.05(-41.74,5.64)$ & 0.14 & $90 \%$ \\
\hline Total contrast used, $\mathrm{ml}$ & 6 & 828 & $-22.64(-33.99,-11.30)$ & $<0.001$ & $56 \%$ \\
\hline Post-procedural mean gradient, $\mathrm{mm} \mathrm{Hg}$ & 6 & 909 & $-0.58(-1.24,0.08)$ & 0.09 & $0 \%$ \\
\hline \multicolumn{6}{|l|}{ SEV patients } \\
\hline Fluoroscopy time, min & 0 & 0 & - & - & - \\
\hline Procedure time, min & 0 & 0 & - & - & - \\
\hline Total contrast used, $\mathrm{ml}$ & 0 & 0 & - & - & - \\
\hline Post-procedural mean gradient, $\mathrm{mm} \mathrm{Hg}$ & 2 & 234 & $0.88(-0.45,2.21)$ & 0.20 & $0 \%$ \\
\hline \multicolumn{6}{|l|}{ Studies published before January $1^{\text {st }} \mathbf{2 0 1 5}$} \\
\hline Fluoroscopy time, $\min$ & 2 & 120 & $-1.05(-3.55,-1.46)$ & 0.41 & $61 \%$ \\
\hline Procedure time, $\min$ & 2 & 120 & $-24.96(-68.07,18.16)$ & 0.26 & $97 \%$ \\
\hline Total contrast used, $\mathrm{ml}$ & 3 & 176 & $-26.28(-40.75,-11.82)$ & $<0.001$ & $18 \%$ \\
\hline Post-procedural mean gradient, $\mathrm{mm} \mathrm{Hg}$ & 3 & 180 & $-0.53(-1.82,0.76)$ & 0.42 & $0 \%$ \\
\hline \multicolumn{6}{|l|}{ Studies published after January $1^{\text {st }} \mathbf{2 0 1 5}$} \\
\hline Fluoroscopy time, $\min$ & 4 & 1169 & $-2.28(-5.47,0.92)$ & 0.16 & $83 \%$ \\
\hline Procedure time, $\min$ & 3 & 388 & $-18.12(-28.95,-7.28)$ & 0.001 & $30 \%$ \\
\hline Total contrast used, $\mathrm{ml}$ & 5 & 1418 & $-18.34(-27.97,-8.72)$ & 0.002 & $42 \%$ \\
\hline Post-procedural mean gradient, $\mathrm{mm} \mathrm{Hg}$ & 8 & 2039 & $-0.43(-0.97,0.11)$ & 0.12 & $23 \%$ \\
\hline \multicolumn{6}{|l|}{ TF cohort } \\
\hline Fluoroscopy time, min & 2 & 569 & $-1.64(-7.02,3.75)$ & 0.55 & $83 \%$ \\
\hline Procedure time, $\min$ & 2 & 301 & $-21.41(-34.30,-8.52)$ & 0.001 & $30 \%$ \\
\hline Total contrast used, ml & 4 & 874 & $-21.46(-30.25,-12.66)$ & $<0.001$ & $0 \%$ \\
\hline Post-procedural mean gradient, $\mathrm{mm} \mathrm{Hg}$ & 6 & 1395 & $-0.37(-1.04,0.29)$ & 0.27 & $28 \%$ \\
\hline
\end{tabular}


$\mathrm{BEV}=$ Balloon - expandable valve; $\mathrm{CI}=$ confidence interval; $\mathrm{MD}=$ Mean difference between direct TAVR and TAVR with $\mathrm{BPD} ; \mathrm{SEV}=\mathrm{Self}-\mathrm{expandable}$ valve . Other abbreviations as in Table 2. 


\begin{tabular}{|c|c|}
\hline Advantages & Drawbacks \\
\hline Improved sizing of the aortic annulus & $\begin{array}{l}\text { Acute aortic regurgitation before valve } \\
\text { implantation }\end{array}$ \\
\hline $\begin{array}{l}\text { Identification of patients at high-risk of coronary } \\
\text { occlusion }\end{array}$ & $\begin{array}{c}\text { Conduction disturbances: left bundle branch and } \\
\text { atrioventricular blocks }\end{array}$ \\
\hline Easier crossing of the aortic valve & Cerebrovascular events \\
\hline $\begin{array}{l}\text { May reduce the risk of valve malposition by } \\
\text { minimizing radial counterforces }\end{array}$ & Annulus rupture \\
\hline Allow optimal expansion of the prosthesis & $\begin{array}{l}\text { May increase valve movement during the } \\
\text { positioning phase }\end{array}$ \\
\hline $\begin{array}{c}\text { Reduced need for postdilation: may improve } \\
\text { prosthesis durability }\end{array}$ & Prolongs the procedure \\
\hline Training of young operators & Increased need for rapid pacing \\
\hline
\end{tabular}

